\title{
Study on the Imbalance and Reconstruction of College English Classroom under Information Ecology
}

\author{
Jingjing Guan ${ }^{1, a}$ \\ ${ }^{1}$ Qiqihar Medical University, Qiqihar, Heilongjiang, 161006 \\ ${ }^{\mathrm{a}}$ email
}

Keywords: Imbalance and Reconstruction, College English Classroom, Information Ecology

\begin{abstract}
Educational information is the inevitable development of the times, but also one of the strategic focuses of Chinese information technology development and the modernization of education. The rapid development of information technology is changing the way of people living, working and thinking, but also changing the way of teaching. Especially in the last decade, college English teaching and modern information technology have been closely linked. Computer network and college English teaching model are widely used in the country and promote the overall level of college English teaching. However, when the position of information technology is more and more higher, there are some problems to be solved in college English teaching.
\end{abstract}

\section{Introduction}

Educational information is another historic revolution in the history of human education, to promote education, reform the educational process and optimize the allocation of educational resources, which has an important role in promoting. College English Teaching in the Context of education information is experiencing with a variety of modern information technology, particularly the deep integration of computer network technology. In the integration process of college English teaching some new phenomena and problems requires in-depth analysis and researching. Classroom teaching as the main battlefield to carry out various activities, it is an interdependent and constitute ecosystem in which ecological factors is a contact by the teachers, students, teaching environment mutually from the perspective of ecology. This study related theories and methods of ecology and systems science, college English classroom Ecology Research Information Context imbalance, analyze the reasons, the principle of ecological reconstruction of university English classroom. Finally, from an ecological perspective, the path and Practical strategies work.

\section{The Structure and Function of College English Class Ecology}

Classroom study English, from the scientific point of view of University ecological systems, which belongs to interdisciplinary research. In order to achieve the interdisciplinary research, the fundamental way is analogy argument. Among them, the "same characteristics", is the premise of this argument which can be established, without it, can not be carried on. For this study, only the first factor with a college English class ecology is an "ecosystem", and can be the basis of this "same characteristics", in the study of college English class system applying the theory of ecology and science. If, as the "College English Classroom with ecological nature, it can be seen as an ecosystem to be studied" as an analogy hypothesis, the hypothesis can get the following three-point support: transverse support 1) inclusive of ecology and systems science from an ecological perspective will be considered system classroom study; 2) predecessors have been from an ecological perspective on classroom teaching a lot of researches, and achieved rich results; 3) having a college English class basic ecosystem structure and function.

Structure "knot" is a combination of contact meaning, "structure" is intended to denote structure, framework, combined with structure, refers to an architectural combination of several components according to a certain relationship, used to represent things state of being. Structure includes two meanings: the components and relationships are what constitutes, what relationship exists. An ecosystem, with the component enough, you also need to have some structure before they can 
operate, can achieve its functions. Ecosystem structure includes two: morphology and trophic structure. Morphology refers to the eco-system in internal and external configuration, texture and color, nutrition structure refers to nutrition as a link to biotic and abiotic closely together to constitute producers, consumers, decomposers as the center of an abstract structure. A basic structure of the ecosystem is relatively clear, biologically (by function can be divided into producers, consumers and decomposers) and abiotic environment (can be divided into inorganic substances, organic compounds and climatic factors) constituted of their interaction. If not only in a specific particular ecosystem, and the categories of individuals, the environment etc. constitutes of different organisms, but also in the emergence of different external presentation forms, which affected trophic structure, and therefore it is inconvenient to use a unified graphical representation, however the internal the basic structure can still be abstracted. Nutrition structure producers, consumers, decomposers are based on their function in the ecosystem of the division and regardless of the taxa, it is also known as the three functional groups ecosystem. Energy from the sun through photosynthesis, or the role of the producer can enter the ecosystem, step by step flow forming ecosystem trophic structure of the three functional groups.

\section{College English Class Ecological Imbalances at Information Age}

Reasonable structure will form a stable system, irrational structure will be composed of an unstable system, the structure reflects the overall order and organization between the elements, which is based on internal coordination system or disorders, the system can no functions to achieve its fundamental premise. College English class ecological reform before 2004 is in steady state equilibrium, the system ecological factors (teaching elements) after the long teaching practice of running, has been in relatively good compatible state, the system is relatively stable, but also begin to show an inert, classroom productivity began to drop decline.

From all system functions, the system is composed by a number of elements and by interacting, interrelated, mutual restraint of the whole has a certain function. The combination of classroom study ecology and ecological classroom performance characteristics of the system of internal structure, internal relations, the role of the system as a whole as well as the external environment (social) generated by the induction of the four functions, namely, optimization of the structure, the relationship between tuning function, promote functional and ecological function of the evolution of educating people. College English Classroom Context Ecological information appears on the offset function, which showed attenuation of these four functions.

Unlike collection system, set just a few scattered persons or things to come together, but it is some of the elements of the system together after polymerization to produce interaction between the various elements, interrelated, mutual checks and balances. It is the interaction force between these elements, drawing the various elements of the ongoing self-adjustment, and finally to achieve individual elements of quality and quantity, in harmony with other system components, so that the whole system is into a relatively stable, relatively balanced status. In nature, ecosystems have this self-organization, eventually drawing the natural balance of the state system, but the whole process will be very slow. In the social-ecological system, since the body has a strong ecological initiative, the general system will quickly adjust to the equilibrium state, on the contrary, as evidenced by structural optimization function of the system significantly reduced. Information in the process of university English classroom ecology emerged weakened structure optimization, which can be demonstrated by the structure of the system was observed. In the past, College English Classroom Reform Ecological information was in a relatively balanced state of equilibrium for this tremendous disturbance, which is the modern information technology in foreign language teaching in large quantities. The rapid evolution of modern information technology for the classroom environment factors leading factor, disturbance which produces far beyond the system itself self-organizing and self-healing capabilities, which produces a force pulling the other classroom subjects and classroom environment ecological factor of self-regulation self-change, this change has been going on for several years, constitute the proportion of each component in the system is still in the imbalance state, from the time span of the system and the system is now turbulent process of structural state to 
determine the structure optimization, the system weakened, difficult to repair its own balance within the system.

\section{College English Class Ecological Information Context Reconstruction}

IT has a revolutionary impact on the development of education, which is an important force to promote the education model of evolution we must be highly valued. College English teaching reform process information, an accurate understanding of information technology in the classroom which helps to give full play the leading role of information technology, driven by factors other classroom ecological structure and function of adjustment to repair because of the early reform extensive application of information technology to the classroom and caused ecological imbalance. Based on the information of the college English teaching reform has advanced in recent years, the majority of educators in information technology in foreign language teaching an important position as a dominant factor has also been gradually clear understanding. Many scholars believe that the computer network and other information technology in foreign language teaching techie should with the deepening of reform and change, the initial auxiliary teaching function should be transformed into an important force to guide teaching reform, and largely determines the way teachers teach and the way students learn, teachers and students information literacy also largely determines whether it can become a qualified teacher or student. IT is no longer a foreign language teaching unimportant presentation tool, but an indispensable teaching tool teaching, teaching cognitive tools and the main object of existence. Dominance of information technology, once established, other ecological factors ecological classroom certainly moving along, as the main ecological classroom teachers and students will be performing and teaching in order to pursue their own development and take the initiative to change teaching, consciously improve information literacy, positive change teaching methods, the initiative to adjust classroom interaction, classroom ecology as object classroom environment and atmosphere also become the light of classroom rules will be adjusted accordingly, the original classroom ecological imbalance will gradually repair.

Ecology tolerance laws of the view that any ecological factors in the quantity or quality are insufficient or excessive, that is when it approached or reached the limits of tolerance of an organism will affect or even prevent the kinds of biological survival, growth, reproduction, distribution and diffusion, become a limiting factor in the ecosystem. In the classroom ecology, the interaction between ecological factors, are well received by the impact of other factors within the system, which in turn affects the other factors, and ultimately affect the growth of eco-classroom subject. When this effect is approached or reached the limits of tolerance ecological classroom subject, then it evolved into a limiting factor undermining the classroom ecological balance and harmony. To reconstruct the ecological balance of the foreign language classroom, it is necessary to control the classroom ecology limiting factor.

Niche theory holds that populations of individual species or ecosystem have their own niche, that certain space-time location and function, and thus maintain the normal operation of the system. Educational Ecology Perspective niche subject is not limited to stocks and species, but includes all the components of the system. Therefore, classroom teaching ecology in all the elements, including teachers, students, teaching materials, teaching methods, information technology, classroom layout, rules and regulations, etc., has its own niche. After the strong involvement of western information technology classroom teaching, classroom gradually evolved into the dominant factor, bringing the internal system of niche overlap, niche separation, niche specialization and other issues affecting the harmonious relations between the various components of the system, resulting in the imbalance of the system. To reconstruct the ecological college English class, we must adjust the niche classroom ecological factors.

College English Classroom Context Ecological information appeared imbalances, imbalance is one of the important characteristics of classroom ecosystem components constitute at the emergence of this structural imbalance is mainly because the internal system components didn't have synchronization covariant with information technology. To reconstruct College English Classroom Context of ecological information, it must take the initiative to intervene, trying to boot the system 
components with the involvement and change.

\section{Conclusion}

In this study, from the perspective of ecology and systems relevant theories of science, according to the basic ideas of identify problems, describe problems, analyze problems and solve problems on college English classroom Ecological Context information system. It ultimately proposed digestion college English class ecological imbalances strategy and initiatives. This paper has briefly reviewed the main points proposed in this study, to reflect problems and deficiencies existed in the research and outlook on the future direction of this topic for further research.

\section{Acknowledgements}

2015 annual economic and social development in Heilongjiang key research project (Foreign Language special disciplines) Title: College English classroom ecosystems IT Vision of the effective implementation and project number: WY2015020-B.

\section{References}

[1] Algozzine, K. M.; et al. (1986). Classroom Ecology in Categorical Special Education Classrooms: And so, They Counted the Teeth in the Horse! Journal of Special Education, 2, 209-217.

[2] Ashby, E. (1966). Universities: British, Indian, African: a Study in the Ecology ofHigher Education. Cambridge: Harvard University Press.

[3] Barowy, W. \& Smith, J. E. Ecology and Development in Classroom Communication. Linguistics and Education, 19, 149-165.

[4] Becker, F. D., Sommer, R. Bee, J. \& Oxley, B.. College Classroom Ecology. Sociometry, 4, 514-525.

[5] Boylan, M. Ecologies of Participation in School Classrooms. Teaching and Teacher Education, 26, 61-70.

[6] Brooks, C. I. \& Rebeta, J. L. College Classroom Ecology-The Relation of Sex of Student to Classroom Performance and Seating Preference. Environment and Behavior, 3, 305-313. 